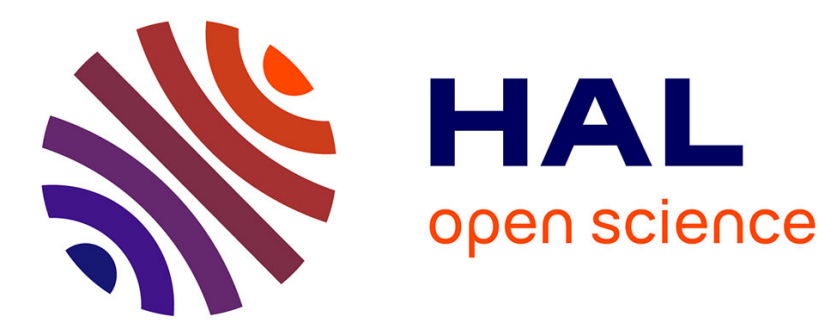

\title{
Volumes de bois exploités en France en 1989
}

Jean Pardé

\section{- To cite this version:}

Jean Pardé. Volumes de bois exploités en France en 1989. Revue forestière française, 1991, 43 (6), pp.519-520. 10.4267/2042/26237 . hal-03425268

\section{HAL Id: hal-03425268 \\ https://hal.science/hal-03425268}

Submitted on 10 Nov 2021

HAL is a multi-disciplinary open access archive for the deposit and dissemination of scientific research documents, whether they are published or not. The documents may come from teaching and research institutions in France or abroad, or from public or private research centers.
L'archive ouverte pluridisciplinaire HAL, est destinée au dépôt et à la diffusion de documents scientifiques de niveau recherche, publiés ou non, émanant des établissements d'enseignement et de recherche français ou étrangers, des laboratoires publics ou privés. 


\section{économie et forêt}

\section{VOLUMES DE BOIS EXPLOITÉS EN FRANCE EN 1989}

L'Assocation Forêt-Cellulose (AFOCEL) publie, chaque année, un mémento de petit format, et d'une vingtaine de pages, remarquable par la densité et la clarté de la documentation chiffrée qu'il fournit sur l'économie forestière française, vue notamment sous l'angle des industries des pâtes, papiers et panneaux de fibres ou particules.

Les indications données sur la "production commercialisée de l'exploitation forestière en 1989 " sont particulièrement dignes d'intérêt pour nos lecteurs.

II s'agit de volumes exprimés en totalité sur écorce.

On pourra les comparer - avec une indulgente précaution - aux volumes du genre pour 1988 , tels qu'ils ont été "calculés" dans le $n^{\circ} 6 / 1990$ de la Revue forestière française (page 615, tableau $=$ " récolte $"$.

\begin{tabular}{|c|c|c|}
\hline En millions de $\mathrm{m}^{3}$ & 1988 * & 1989 ** \\
\hline Grumes feuillues & 10,5 & 9,7 \\
\hline Grumes résineuses & 15,0 & 14,0 \\
\hline Bois d'industrie feuillu .... & 5,0 & 5,3 \\
\hline Bois d'industrie résineux $\ldots \ldots \ldots \ldots \ldots \ldots \ldots$ & 5,5 & 7,2 \\
\hline \multirow{2}{*}{ Bois de feu commercialisé $\ldots \ldots \ldots \ldots \ldots \ldots \ldots$} & 1,5 & 2,7 \\
\hline & 37,5 & 38,9 \\
\hline
\end{tabular}

- Source: Revue forestière française.

" Source: AFOCEL. 
J.P.

Les bases sont chaque fois les mêmes: les enquêtes annuelles de branche du Service central des Enquêtes et Études statistiques (SCEES) du ministère de l'Agriculture et de la Forêt. Mais les passages des volumes sous écorce aux volumes sur écorce ont pu motiver ensuite des divergences " artificielles" dans le cas des résineux.

Se référant à la suite annuelle antérieure de ses statistiques, l'AFOCEL admet " une hausse de la production 1989 de $3 \%$ par rapport à celle de 1988, et de 11,8\% par rapport à 1987 ".

Nous sommes d'accord sur cette appréciation.

Reste le problème difficile du bois autoconsommé - bois de feu pour l'essentiel - "n'empruntant pas les circuits habituels de commercialisation".

Nous reportant à des études déjà anciennes, nous avions admis, dans la Revue forestière française, le chiffre approximatif de 20 millions de mètres cubes annuels.

C'est là une évaluation sans doute excessive.

Le bulletin 1991 du ministère de l'Agriculture et de la Forêt, édité sous le titre "L'agriculture française en chiffres" par le SCEES, annonce 15 millions de mètres cubes de bois de feu annuellement autoconsommés en France.

Le mémento 1991 de l'AFOCEL est encore plus réservé : se référant à l'Agence française pour la Maîtrise de l'Énergie (AFME), il admet que le volume en question ne dépasse pas maintenant 12 millions de mètres cubes.

En fait, toutes les estimations du genre semblent mal étayées, et donc peu crédibles. 